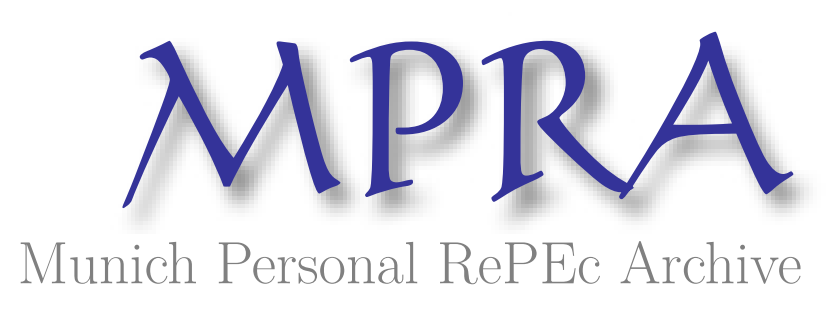

\title{
Task Specialization, Wage, and Immigration in Canada
}

Jiang, Shiyu

2 November 2020

Online at https://mpra.ub.uni-muenchen.de/103988/

MPRA Paper No. 103988, posted 12 Nov 2020 06:51 UTC 


\title{
Task Specialization, Wage, and Immigration in Canada
}

\author{
By Shiyu Jiang
}

\begin{abstract}
This paper uses Canadian census data to undertake research on the effects of immigration on employees' performance in the Canadian labor market. By generating a new method to define communication and manual tasks, this paper concentrates on changes in task supplies in the labor market resulting from changes in immigration to Canada. This paper also studies the effects of a change in the foreign-born worker share on task compensations. In this paper, the Canadian labor market is separated into two groups based on workers' educational attainments, and these two groups have different reactions to an increase in the share of immigrant workers in the labor market. Using a regression model, I estimate compensations for communication and manual tasks respectively to study how relative compensation variation is affected by the foreign-born worker share. I find some important evidence of immigration effects on the Canadian labor market, and these effects vary across metropolitan areas and years. The increase in the foreign born share will lead both the relative supply of communication versus manual tasks and the relative compensations of these tasks to go up in the highly-educated workers group. However, the Canadian immigration does not impact the less-educated group quite significantly because of the smaller size of this group in the labor market.
\end{abstract}




\section{Introduction}

In recent years, more and more people are immigrating to Canada. From Statistics Canada, we can find that:

- In 2011, Canada had a foreign-born population of about 6,775,800 people. They represented $20.6 \%$ of the total population, the highest proportion among the G8 countries.

- Between 2006 and 2011, around 1,162,900 foreign-born people immigrated to Canada. These recent immigrants made up $17.2 \%$ of the foreign-born population and $3.5 \%$ of the total population in Canada.

- Asia (including the Middle East) was Canada's largest source of immigrants during the past five years, although the share of immigration from Africa, Caribbean, Central and South America increased slightly.

The vast majority of the foreign-born population lived in five provinces: Ontario, British Columbia, Quebec and Alberta, and most lived in the nation's largest urban centers such as Toronto, Vancouver, Montreal, and so on.

In the 1990s, educational attainment among new immigrants increased significantly. For example, while about one-quarter of male immigrants who landed in 1988 had a university degree, this was the case for over one-half of those who landed in 1999. Among female immigrants who landed in 1988, $18 \%$ had a university degree. By 1999, that proportion had risen to $42 \%$.

Some Canadians believe that current immigration level are too high. Inherent in this pessimism over perceived high immigration levels is the belief that it could potentially lead to loss of Canadian jobs, wage suppression or increased unemployment insurance and welfare rolls, thereby putting pressure on the public treasury (Baker and Benjamin: 1995).

Canada has a well known "points system" for independent immigration. In 1978, the Parliament of Canada enacted "Immigration Act, 1976" to refuse those independent immigrants who could become a burden on social welfare or health services. This act was replaced by "Immigration and Refugee Protection Act, 2001" in 2002. We may infer a different competition situation between highly-skilled immigrants and natives in Canada from that in the US.

Some argue that, when more immigrants come, it becomes harder for natives to get a good job. On the other hand, with more immigrants, Canada will experience faster economic development. In order to study how immigration impacts natives and the overall working population in the Canadian labor market, this paper adopts the approach used in a paper written by Peri and Sparber (2009). Peri and Sparber (2009) introduce a way to decompose jobs into a combination of communication and manual task supplies. By generating these two task supplies per unit of time for each occupation, workers' task productivity can be derived in each occupation. Then, by looking at the changes in the average task productivity in each city in different years, we could tell if the native workers and the total population 
are transferring to communication-intensive or manual-intensive jobs as a consequence of immigration to Canada.

This paper studies the effect of immigration on task specializations. This paper follows Peri and Sparber's structure (2009), and tries to find evidence of immigration effects on Canada's labor market. Instead of using the O*NET abilities survey from the US department of labor, I use a new dataset called the Canadian Career Handbook to define each occupation's composition of specific aptitudes. This is appropriate because I assume employees with the same occupation may perform differently in Canada and the US. Then I create new definitions for task specializations. ${ }^{1}$ After that, I match occupations in the Canadian Career Handbook with those in the Canadian Census to generate a combined dataset which includes employees' characteristics and their occupations' detailed features.

In Canada, there is an existing literature about the effects of immigration on labor market. For instance, some papers (Laryea 1998a and Laryea 1998b) explore the substitutability or complementarity between natives and immigrants to determine whether immigrant inflows hampered the economics progress of native employees, or if job opportunities of the native-born worsen because of large inflows of foreign-born workers. Some other papers (Schaafsma and Sweetman 2001, Picot and Sweetman 2005, and Aydemir and Borjas 2006) examine the relationship between immigration and the unemployment rate as well as earnings in the Canadian labor market. In this paper, I will focus on understanding how native-born workers transfer to different types of occupations (communication or manual intensive occupations) because of the immigrant inflows. In other words, will native workers alter the composition of their tasks supply when they are facing the large pool of immigrants in the labor market?

Intuitively, it is expected that natives would shift to more communication-intensive jobs in response to the increase of immigrants in one country. In the US, the majority of the immigrants come from Mexico and are believed to be weak at English language. This background would push these Mexicans' competitors to increase their communication task supply and decrease their manual task supply to avoid a huge loss from the manual task supply competition. In Canada, the composition of immigrants is quite different from that in the US. However, the same shifting in task supply may still occur. Immigrants to Canada are believed to have good language skills; however, most of them still cannot use Canada's official languages as well as natives because they come from non-English speaking source countries. Natives still have an advantage in communication-intensive tasks, so that they still could shift to a more communication-intensive job to avoid a further economic loss from the manual task supply competition. Moreover, immigrants to Canada are typically wealthy and have high job skills. Therefore, the increase of these kinds of immigrants would generate demand for high skilled and communication intensive jobs like the finance advisor, investment consultant, estate agent, and new immigration service job positions, which will have an incentive to the natives. This is why I expect that natives will also shift to more communication-intensive jobs in response to an increase in the foreign-born worker share in Canada.

\footnotetext{
${ }^{1}$ The details for this part will be presented in Section 4 .
} 
In this paper, motivated by Peri and Sparber (2009), I study the impacts of the increasing number of the immigrants on changes in workers' task supplies in the Canadian labor market. In Section 3, I redo the theoretic procedures in Peri and Sparber's paper (2009) but allow high skilled occupations to be more or less communication intensive as well so that I generate a series of new regression models more suitable for my study. Moreover, I introduce my data sources and new methods to generate communication and manual tasks as well as an instrumental variable for the 2SLS estimations in Section 4.

In the next section, I present my empirical results. First, in Section 5.1, I show the impacts of the increasing foreign born worker share on the change in the natives' supplies of communication and manual tasks. I find that, with the increase of the foreign born share, both highly-educated and lowereducated natives increase their relative supplies of communication tasks relative to manual tasks i.e. the natives transfer to communication-intensive occupations in general. However, highly-educated native workers increase their communication task productivity and decrease their manual task productivity, but lower-educated natives only increase their communication task productivity but do not change their manual task productivity significantly. This might be because less educated workers are less likely to hold technology-intensive jobs.

After this, in Section 5.2, I study the effect of immigration on the relative task supply changes of the total working population in the Canadian labor market. I find that, because of the dramatic increase in the demand for the communication intensive jobs in Canada, the increase in the foreign born share could lead the relative task supplies of the highly-educated workers to be more communicationintensive. Because there are few lower-educated immigrants, they are considered not to trigger a significant impact on the relative task supplies of the total lowder-educated population.

In Section 5.3, I link changes in the relative compensation of communication versus manual tasks to the increasing foreign born share. I find that, in the highly-educated group, an increase in the number of immigrant workers causes the relative compensation of communication versus manual tasks to go up. This might result from the large proportion of the wealthy class among all the immigrants coming to Canada. The higher elasticity of the complementary relationship between the foreign born share and the wages of lots of communication-intensive industries in Canada dominantly lead such an increase. Lastly, in Section 5.4, I divide the natives into some comparison groups based on different demographic characteristics and demonstrate differences in the impact of immigration on relative task supplies within each comparison group.

\section{Literature Review}

Peri and Sparber (2009) found that immigration to the US causes natives to supply more communication tasks to avoid potential wage loss. Peri and Sparber argued that since immigrants to the US have poor English language ability, they would cause a substitution effect for manual tasks instead of 
communication tasks.

This is quite different from the situation in Canada. Bonikowska, Hou, and Picot claim that even after accounting for compositional shifts, immigrants with high education experience different earnings outcomes in Canada and the US. Schaafsma and Sweetman (2001) showed that only the immigrants with a Canadian educational background could perform as well as the Canadian born, while those without a domestic educational background could not. In Canada, recent immigrants are believed to be quite different from older immigration cohorts. Picot and Sweetman (2005) argued that the increasing low-income rates resulted from the changing characteristics of immigrants, including country of origin; language; the decreasing returns to foreign work experience; and the decline in the labor-market outcomes of all new labor-force entrants including immigrants. Aydemir and Borjas (2006), we learn that a $10 \%$ labor-supply shift caused by immigration would result in a $3 \%$ to $4 \%$ reduction in wages in Canada.

A paper written by Goldin and Katz (2007) claims that "high school graduates and dropouts are close substitutes today." Then, Ottaviano and Peri (2008) find that there is a significant degree of imperfect substitutability between workers with a high school diploma or less and those with some college education or more. Therefore, in this paper, we will define two groups of workers based on educational attainment. One consists of workers with a high school degree or less, and the other consists of workers with more than high school degree. Therefore, to study the precise substitution effects from immigrants, I will study these two educational groups of workers separately. My analysis treats skilled and unskilled workers as belonging to separate labor markets, but this may not be entirely accurate since it is possible that high skilled immigrants compete with low-skilled natives. In future work I will treat unskilled natives and all immigrants as a single labour market to obtain some new findings.

There is mixed evidence about the effect of immigration on natives' wages. Immigration may not affect natives' employment or wages if immigrants and natives are imperfect substitutes in production. Peri and Sparber (2009) showed that immigration from Mexico induces native born workers to shift from manual to communication intensive tasks. These facts encourage us to make comparisons within substitutable groups. In this paper, workers are considered to be substitutable with each other only in their own educational groups.

When we study the immigration effects on the wages in the Canadian labor market, there are some other early relevant papers. Laryea (1998a) applies a random effects model to analyze the impact of foreign-born workers on wages in Canada. He studies the impacts by broad industry group and gender. Finally, the empirical results give the conclusion that there appears to be complementary relationship between Canadian wages and foreign-born wages, but the relationship has been masked by developments in specific industries.

After this, Laryea (1998b) employs a generalized Leontief production function to study whether there exists substitutability or complementarity between Canadian, old foreign-born and new foreign- 
born workers using data from the 1991 census. The results show that Canadian and new foreign-born workers are substitutable in production with adverse impacts on Canadian-born wages. The earlier immigrants, on the other hand, were found to be complements to Canadian-born workers. Moreover, he proved that the foreign-born share in the Canadian labor market has a complementary relationship with Canadian wages in some communication-intensive industries while a substitutable relationship in other industries. Meanwhile, the complementary wage elasticity of the foreign-born share is higher than the substitutable part. Therefore, we could expect an increase in the relative compensation of the communication task versus the manual task caused by the increasing foreign-born worker share.

Some recent papers put views on the skill transition of women in Canada. Adserà and Ferrer (2014) find that, judging by the gradual convergence between the tasks required for educated immigrant women's jobs and those of natives, the job barriers seem to ease over time and lead to some wage assimilation (up to 80 percent of the wages of similar native-born women after 15 to 20 years in Canada). Moreover, they claims skill progression does not happen to less educated immigrant women, although wages still rise gradually over time. Adserà and Ferrer (2016) show that, on average, immigrant women participate significantly more in the labour market and experience wage gains over time, even though the skills required by their jobs do not converge to those of natives. They use recent evidence in Canada to show that married immigrant women make labor supply decisions similar to those recently observed for native married women.

In my paper, I will study the immigration effects on these two areas similarly as Laryea did by introducing task specialization into the research.

\section{Theoretical Model $^{2}$}

\subsection{Regular Model}

Now, I propose a general equilibrium model of task performance to demonstrate the effects of immigration on specialization and wages. First, consider an open economy that combines two nontradable intermediate services, $Y_{H}$ and $Y_{L}$, we denote the a CES production function to produce a final tradable consumption good, $\mathrm{Y}$.

$$
Y=\left[\beta Y_{L}^{\frac{\sigma-1}{\sigma}}+(1-\beta) Y_{H}^{\frac{\sigma-1}{\sigma}}\right]^{\frac{\sigma}{\sigma-1}}
$$

Parameter $\sigma \in(0, \infty)$, and $\beta \in(0,1) . \sigma$ measures the elasticity of substitution between $Y_{H}$ and $Y_{L}$, while $\beta$ capture the relative productivity of these two intermediate services. In this paper, we will focus on the effects within both the highly-educated and less-educated workers which is different from Peri \& Sparber's idea (2009). So, I assume that workers in both these two educational groups are heterogeneous and may differ in their relative task productivity. Now, we define relative supply of

\footnotetext{
${ }^{2}$ This Structure is from Peri \& Sparber (2009)
} 
tasks as communication and manual tasks. This paper will focus on the less educated workers. Now, we define the intermediate service from low educated workers as:

$$
Y_{i}=\left[\beta_{i} M_{i}^{\frac{\theta_{i}-1}{\theta_{i}}}+\left(1-\beta_{i}\right) C_{i}^{\frac{\theta_{i}-1}{\theta_{i}}}\right]^{\frac{\theta_{i}}{\theta_{i}-1}}
$$

Where $\beta_{i}$ and $\theta_{i} \in(0, \infty) . \mathrm{i}=\mathrm{H}$ or L. Here, $\mathrm{M}$ and $\mathrm{C}$ mean the units of manual- and communication-tasks inputs in the aggregate.

Consider the case when labor markets here have perfect competition among producers of $Y_{H}$ and $Y_{L}$ respectively, which is a very strong assumption. Then, we have the equation (3), where $w_{C}$ and $w_{M}$ denote the compensation (price) paid for one unit of manual and communication task, respectively.

$$
\frac{C_{i}}{M_{i}}=\left(\frac{1-\beta_{i}}{\beta_{i}}\right)^{\theta_{i}}\left(\frac{w_{C i}}{w_{M i}}\right)^{-\theta_{i}}
$$

Labor incomes are given in equations (4) and (5) for the native and immigrant workers, respectively. Here, it is assumed that both of the highly and lower educated workers share the same income functions.

$$
\begin{gathered}
w_{D i}=\left(l_{D i}\right)^{\delta} \mu_{D i} w_{M i}+\left(1-l_{D i}\right)^{\delta} \varsigma_{D i} w_{C i} \\
w_{F i}=(1-d)\left[\left(l_{F i}\right)^{\delta} \mu_{F i} w_{M i}+\left(1-l_{F i}\right)^{\delta} \varsigma_{F i} w_{C i}\right]
\end{gathered}
$$

$(1-d) \in(0,1)$.

Again, "i" is a worker's education group. D and F denote native-born and foreign-born workers, respectively. Let $l_{j}$ be the share of a worker's labor endowment for manual tasks in his or her occupation with respect to a unit of time. Then, a worker's supply of manual task units is $m_{j}=\left(l_{j}\right)^{\delta} \mu_{j}$, while the supply of communication task units is $c_{j}=\left(1-l_{j}\right)^{\delta} \varsigma_{j}$. By maximum these two equations with respect to $l_{j i}$, we can get:

$$
\frac{c_{j i}}{m_{j i}}=\left(\frac{w_{C i}}{w_{M i}}\right)^{\frac{\delta}{1-\delta}}\left(\frac{\varsigma_{j i}}{\mu_{j i}}\right)^{\frac{1}{1-\delta}}
$$

and

$$
\frac{l_{j i}}{1-l_{j i}}=\left(\frac{\varsigma_{j i} w_{C i}}{\mu_{j i} w_{D i}}\right)^{\frac{1}{1-\delta}}
$$

Then, let $L_{j}$ be the total labor supply of group j, we can denote the equation (8) as the aggregate relative supply of tasks in the economy.

$$
\frac{C_{i}}{M_{i}}=\frac{C_{F i}+C_{D i}}{M_{F i}+M_{D i}}=\varphi_{i}\left(f_{i}\right) \frac{C_{F i}}{M_{F i}}+\left(1-\varphi_{i}\left(f_{i}\right)\right) \frac{C_{D i}}{M_{D i}}
$$

where $\varphi_{i}\left(f_{i}\right)=\left(M_{F i} /\left(M_{F i}+M_{D i}\right)\right) \in(0,1)$, and $f_{i}=L_{F i} /\left(L_{F i}+L_{D i}\right)$.

From equation (3), (6) and (8), we can solve for the equilibrium relative compensation of tasks for 
the two educational groups respectively based on the different "i":

$$
\frac{w_{C i}^{*}}{w_{M i}^{*}}=\left(\frac{1-\beta_{i}}{\beta_{i}}\right)^{\frac{(1-\delta) \theta_{i}}{(1-\delta) \theta_{i}+\delta}}\left[\frac{\varsigma}{\mu}\left(f_{i}, \frac{\varsigma_{F i}}{\mu_{F i}}\right)\right]^{\frac{-1}{(1-\delta) \theta_{i}+\delta}}
$$

Substitute (9) into (6), we will solve for the equilibrium relative provision of tasks.

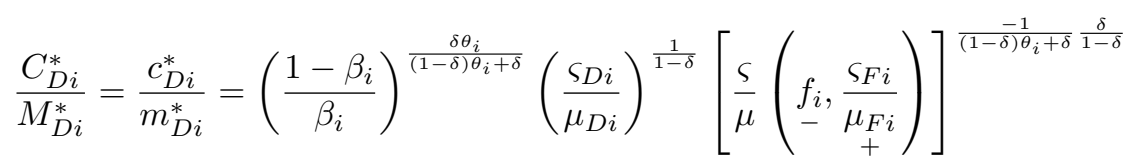

Similarly, we can get the $\frac{C_{F}^{*}}{M_{F}^{*}}$, then, use (8), we will identify the equilibrium aggregate relative provision of tasks.

$$
\begin{gathered}
\frac{C_{F i}^{*}}{M_{F i}^{*}}=\frac{c_{F i}^{*}}{m_{F i}^{*}}=\left(\frac{1-\beta_{i}}{\beta_{i}}\right)^{\frac{\delta \theta_{i}}{(1-\delta) \theta_{i}+\delta}}\left(\frac{\varsigma_{F i}}{\mu_{F i}}\right)^{\frac{1}{1-\delta}}\left[\frac{\varsigma}{\mu}\left(\begin{array}{c}
f_{i}, \frac{\varsigma_{F i}}{\mu_{F i}} \\
+
\end{array}\right)\right]^{\frac{-1}{(1-\delta) \theta_{i}+\delta} \frac{\delta}{1-\delta}} \\
\frac{C_{i}^{*}}{M_{i}^{*}}=\left(\frac{1-\beta_{i}}{\beta_{i}}\right)^{\frac{\delta \theta_{i}}{(1-\delta) \theta_{i}+\delta}}\left[\frac{\varsigma}{\mu}\left(\begin{array}{c}
f_{i}, \frac{\varsigma_{F i}}{-} \\
\mu_{F i} \\
+
\end{array}\right)\right]^{\frac{\theta_{i}}{(1-\delta) \theta_{i}+\delta}}
\end{gathered}
$$

$\frac{\varsigma}{\mu}\left(f, \frac{\varsigma_{F}}{\mu_{F}}\right)$ is a weighted average of the relative skill endowments among natives and immigrants. ${ }^{3}$

Equations (9)-(12) give us the equilibrium conditions. Consider other parameters as given, we could treat $f$ (foreign-born share) as an exogeneous variable which will influence the equlibrium conditions. Thus, we can generate the empirical specifications from these three equations.

\subsection{Empirical Specifications}

Based on equations (10) and (12), we will define three linear regression models by taking log-linearization to those two in the empirical works, and all these equations apply separately to high or low education workers.

$$
\begin{gathered}
\ln \left(\frac{C_{D}}{M_{D}}\right)_{s t}=\gamma f_{s t}+\alpha_{s}^{D}+\tau_{t}^{D}+\varepsilon_{s t}^{D} \\
\ln \left(\frac{C}{M}\right)_{s t}=\gamma_{T O T} f_{s t}+\alpha_{s}^{T O T}+\tau_{t}^{T O T}+\varepsilon_{s t}^{T O T}
\end{gathered}
$$

\footnotetext{
${ }^{3}$ More specifically, $\frac{\varsigma}{\mu}\left(f_{i}, \frac{\varsigma_{F i}}{\mu_{F i}}\right)=\left[\varphi_{i}\left(f_{i}\right)\left(\varsigma_{F i} / \mu_{F i}\right)^{1 /(1-\delta)}+\left(1-\varphi_{i}\left(f_{i}\right)\right)\left(\varsigma_{D i} / \mu_{D i}\right)^{1 /(1-\delta)}\right]^{1-\delta}$.
} 
Then, by log-linearizing the equation (9), we obtain the a third linear relation given by:

$$
\ln \left(\frac{w_{C}}{w_{M}}\right)_{s t}=\gamma_{w} f_{s t}+\alpha_{s}^{w}+\tau_{t}^{w}+\varepsilon_{s t}^{w}
$$

These three panel regressions are my main empirical specifications. Peri and Sparber's paper (2009) studied a similar case in the US; however, in this paper, I use confidential census data ${ }^{4}$ from Statistics Canada and a new approach to define the task variables. Then, I will study the results in Canada and make a comparison with those in the US to see the similarities and differences.

Since the immigrants moving to Canada are quite different from those to the US, we may consider a different equilibrium of the supply and demand of the $\mathrm{C} / \mathrm{M}$ ratio under the relative compensation of communication versus manual tasks which is $W_{c} / W_{m}$. I find the equilibrium under different situations. Figure 2 shows the original equilibrium of the supply and demand of the $\mathrm{C} / \mathrm{M}$ ratio. Figure 3 displays the situation in the US after a large influx of unskilled immigrants from Mexico. The supply of $\mathrm{C} / \mathrm{M}$ would shift leftward since there is a higher poor-English labor share in the market. This will lead to a decrease to $\mathrm{C} / \mathrm{M}$ but an increase to $W_{c} / W_{m}$.

The situation in Canada may be quite different from the US. Since the immigrants to Canada are overwhelmingly formed by the Economy Class (business people and skilled workers) from nonEnglish speaking countries, we could naturally suppose that an increase in the number of immigrants will increase the demand for communication intensive jobs which means the demand curve will shift rightward. Figures 4, 5, and 6 illustrate three different possible results of the leftward shift of the demand curve. First, if the increase in demand resulting from increased immigration is small, in equilibrium, relative compensation will still increase while the equilibrium $\mathrm{C} / \mathrm{M}$ ratio will decline. The second case is a special case. Here, the increase of $\mathrm{C} / \mathrm{M}$ from the rightward shift of the demand curve will be offset by the leftward shift of the supply curve. Therefore, in equilibrium, relative compensation will increase, while $\mathrm{C} / \mathrm{M}$ will stay the same. Finally, in the last figure, if there is a large increasing effect on the demand for communication intensive jobs, the demand curve will shift rightward dramatically. Then, equilibrium relative compensation will increase, and equilibrium $\mathrm{C} / \mathrm{M}$ ratio will increase, too.

\section{Data}

\subsection{Data Source}

The microdata used for my study is census data ${ }^{5}$. from Statistics Canada. I use data for the period 1971-2011, which includes Canada-born and foreign-born (immigrant) workers who are between 18 and 65 years of age. The data include different types of demographic characteristics such as race, birth

\footnotetext{
${ }^{4}$ This will be introduced in Section 4 .

${ }^{5}$ This set of data is the confidential version which is from the RDC department
} 
place, sex, wage, working hours, immigration status, and so on. And for my panel study, I will use metropolitan area to define location. Here might be a potential problem that treating different cities as distinct labor markets may be not fair if they are connected by transit. Therefore, in future work, I will try some other fixed effects (e.g. group cities that are part of the same transit network).

To define the communication and manual tasks for each occupation, I will use another data set from Statistics Canada, which is called the Canadian Career Handbook published in 2003. This data set uses values to define the aptitudes requirement for each occupation: General Learning, Verbal, Numerical, Spatial Perception, Form Perception, Clerical Perception, Motor Coordination, Finger Dexterity, and Manual Dexterity. Each aptitude is given five values (1-5) to describe its grade among the entire working population ${ }^{6}$. However, to undertake my empirical analysis, I will need to generate a new variable to describe the importance of each aptitude. Here, I will use the median of each aptitude's percentile range among all workers to represent that aptitude's importance. For example, the median of the highest 10 percent is 0.95 . Then, I will replace the value 1 by 0.95 . Using this method, I will get 0.75 for the value $2,0.50$ for $3,0.25$ for 4 , and 0.05 for 5 .

To define communication-intensive tasks, I will use the average importance value of Verbal and Clerical Perception aptitudes. When it comes to manual tasks, I have two types of definitions, the basic definition and the extended one. Under the basic definition, a manual task is considered to be a combination of Finger and Manual Dexterity aptitudes. A combination of these two basic aptitudes plus Spatial Perception and Form Perception constitute the extended definition.

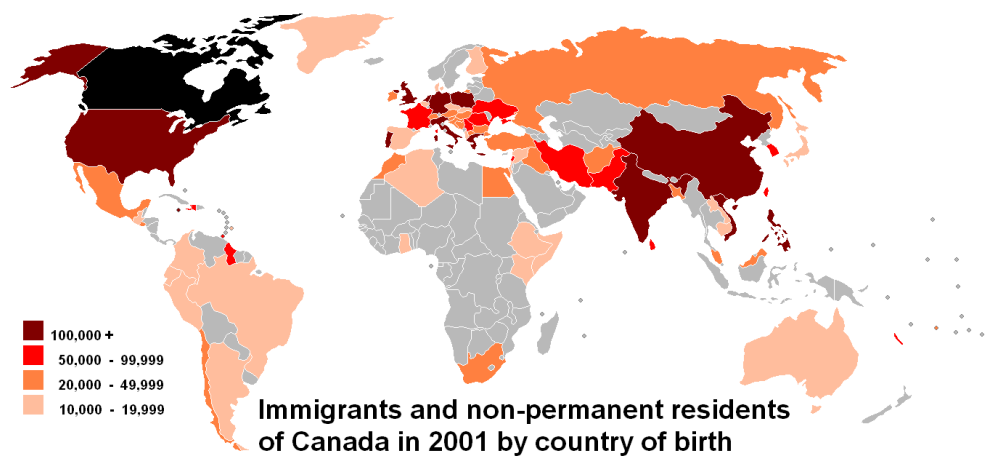

Figure 1: Immigrants situation in Canada

Figure 1 plots the number of immigrants and non-permanent residents of Canada from different source countries in 2001. From this graph, we can see that majority of the foreign-born residents were from China, India, The US, and some European countries. This implies that the immigrants could

\footnotetext{
${ }^{6}$ The value 1 means the aptitude for this occupation is in the highest 10 percent among all workers. The value 2 means the upper third, exclusive of the highest 10 percent. The value 3 means the middle third. The value 4 means the lowest third, exclusive of the lowest 10 percent. The value 5 means the lowest 10 percent.
} 
have quite a different effect on the Canadian labor market than they have on the labor market in the US.

From the graphs (available upon request) showing the relationship between $\mathrm{C} / \mathrm{M}$ ratio and foreignborn shares, I find that that a rise in foreign-born share is associated with an increase in the relative C/M task supply from less-educated natives living in all metropolitan areas during 1971-2011. Then, we could easily find that these two factors still have a positive relationship in the very recent census year, which gives a strong support for the lasting of the relationship between the $\mathrm{C} / \mathrm{M}$ ratio and the foreign-born share. When it comes to the highly-educated group, similar to the less-educated group, $\mathrm{I}$ find a rise in the foreign-born share will also lead to an increase in the $\mathrm{C} / \mathrm{M}$ ratio among highlyeducated native workers in metropolitan areas during the whole period. Moreover, an increase in the foreign-born share still has a positive relationship with the relative $\mathrm{C} / \mathrm{M}$ task supply within the highlyeducated group in all metropolitan areas. If we check the data, we could easily find that the proportion of less educated workers in 1971 is about $91 \%$ which is much larger than other census years in this study. Therefore, the highly educated workers could gather in the jobs which have extremely high $\mathrm{C} / \mathrm{M}$ ratios because these jobs like managers, analysts, officers and so on are all communication-intensive.

Figure 7 demonstrates the shares of population engaged in highly communication-intensive occupations in Canada. Meanwhile, Figure 8 demonstrates those in five metropolises in Canada: Toronto, Vancouver, Ottawa, Montreal, and Calgary. In these two figures, we can see that the patterns are quite similar nationwide and in the five metropolises, even if the levels are different. The shares of the population engaged in highly communication-intensive occupations in Canada kept increasing during the period 1991-2011. At the same time, the new immigrant population during this period also kept increasing dramatically. Hence, it is possible that the relationship between aggregated $\mathrm{C} / \mathrm{M}$ ratio and the foreign-born worker share should be positive in Canada, which is different from the situation in the US as presented by Peri and Sparber (2009). I will use the empirical strategy described above to uncover the true relationship in next sections.

\subsection{Task Variables}

The Canadian Career Handbook assigns numerical values to describe the importance of 9 distinct employee aptitudes required by each occupation. With this set of data, I can define communication and manual tasks in two ways. One is a basic definition, which defines communication skill as Verbal and Clerical Perceptions and manual skill as Finger and Manual Dexterity. The other is an extended definition, which defines manual skill as Finger and Manual Dexterity plus Spatial Perception and Form Perception. One limitation of my study should be concerned that, using a static occupational skill variable may either understate or overstate changes in immigrants' task supplies over time. However, we could understand task supply change mechanism in this way that, if immigrants transit out of certain occupations as those occupations' skill requirements change, then they might be using similar 
skills over time even if their occupations change. On the other hand, if immigrants stay in similar occupations over time and occupational skill requirements change, then they will be using different skills over time even if their occupations haven't changed.

Table 1 demonstrates 12 types of occupations with the specific relative communication versus manual task supply values. Columns 2 to 4 display the values for communication and manual intensity indexes and the percentile of that occupation's $\mathrm{C} / \mathrm{M}$ ratio among all occupations. The first four rows are those occupations with the highest $\mathrm{C} / \mathrm{M}$ ratio values, and the medium four are those with the average $\mathrm{C} / \mathrm{M}$ ratio while the last four represent those with the lowest ratio. In this table, we can see that management consultants, financial and investment analysts, financial auditors, and loan officers have the highest percentile of communication/manual values. The four occupations related to technical, mining, and armed forces possess medium $\mathrm{C} / \mathrm{M}$ ratio. Finally, what matches our prediction is that laborer-type occupations have the lowest $\mathrm{C} / \mathrm{M}$ ratio values.

Tables 2 and 3 display those occupations with the highest and lowest highly-educated worker shares, respectively, during the census period 1991-2011. In Table 2, which lists the highest highly-educated worker shares, we see that many occupations repeat in these three census years, such as General Practitioner and Family Physician, Specialist Physicians, Veterinarians, and so on. Furthermore, we will clearly find that almost all of these jobs have a very high communication intensity index which is more than 0.50 with a large manual/manual-ext intensity index. This suggests that highly-educated workers provide both excellent communication and manual tasks, although most of the occupations with a higher highly-educated worker share are more communication intensive. Table 3 shows the five occupations with the lowest highly-educated worker share in the years 1991, 2001, and 2011. Similar as those in Table 2, many occupations appear repeatedly in the three census years. All the occupations here have a very low communication intensity index and a low manual intensity index since occupations opened to less-educated workers have low requirements on the job skills. So, these occupations are considered to be relatively manual intensive. Moreover, according to the information in Table 2, we can see that, in the highly-educated group, workers also have different relative task supply ratios. For instance, occupations with a large number of highly-educated workers like the "Medical Sonographers", "Veterinarians", and "Chiropractors" give us the C/M ratios smaller than "1", which supports the basic idea of this paper that, not only the lower-educated occupations but the highly-educated ones also vary in their task supplies.

\subsection{Instrumental Variable}

One concern is that unobservable technology and demand factors, which may differ across provinces, might have simultaneously affected the productivity of communicative tasks and attracted immigrants. To establish causality, we use an instrumental variable (IV), "imputed" foreign workers, which captures a large share of the increase in the foreign-born population from some main source countries, beginning 
in 1971. This IV can be generated by: $I V_{s, t}=\sum \lambda_{c, s, t} I_{c, s, t}$, where $\lambda_{c, s, t}$ is the share of immigrants from country c among all immigrants over time in different metropolitan areas. $I_{c, s, t}$ denotes the share of imputed immigrants from country c among all workers:

$$
I_{c, s, t}=I_{c, s, 1971} \frac{\left(1+g_{c}\right)_{1971-t}}{\left(1+g_{C A}\right)_{s, 1971-t}}
$$

In this paper, the source countries/regions I selected for c include the US, Africa, Caribbean region, China, France, Germany, Greece, India, Netherland, Poland, Portugal, Russia/USSR, and UK. I will use this instrument both for the highly-educated and lower-educated groups, since some of source countries send largely highly-educated immigrants while others send largely lower-educated immigrants. Combining these two types of source countries could make the IV suitable for 2SLS estimations in both these two educational groups because this IV would impact both the highly and lower-educated foreign-born worker shares. Moreover, certain important sending countries in recent years were not sending countries in 1971, which affects accuracy of instrument. Therefore, I would improve the source country selection in future and try to use more detailed geographic areas (e.g. specific African countries instead of Africa as a single group) in this study.

\section{Empirical Results}

\subsection{Effects From Immigration to Natives}

Here, I begin the empirical analysis with the regressions for the immigration effects on the Canadian native group. I will use equation (13) to study the relationship between the foreign-born share and the relative supplies of tasks by native workers within the lower and highly-educated groups separately. In addition, I will use two separate equations to study the relationship between the foreign-born share and natives' unit supplies of communication and manual tasks. These two equations are given by

$$
\begin{gathered}
\ln \left(c_{D}\right)_{s t}=\alpha_{s}^{C}+\tau_{t}^{C}+\gamma^{C} f_{s t}+\varepsilon_{s t}^{C} \\
\ln \left(m_{D}\right)_{s t}=\alpha_{s}^{M}+\tau_{t}^{M}+\gamma^{M} f_{s t}+\varepsilon_{s t}^{M}
\end{gathered}
$$

Table 4 shows the regression results for highly educated group. In columns (1) and (2), I use the least squares estimation, weighting by employment in each year and each CMA. In columns (3) and (4), I present 2SLS estimates, which use the instrument I described in last section. The difference between column (1) and (2) is that I use basic definitions for both communication and manual tasks in (1) while I use the basic definition for communication tasks but extended definition for manual tasks in (2). It is the same case between column (3) and (4). From the results, we can see that the relationship between

the foreign-born share and the relative supply of communication versus manual tasks from native 
highly-educated workers is statistically significant at the $1 \%$ significance level in all four regressions. One thing should be claimed that, while these results are not reported, the first stage $\mathrm{F}$ tests all have very small $p$ values. The results suggest that $1 \%$ increase in the foreign-born share will result in a $0.37 \%$ increase in native's communication-manual task ratio under WLS and a $0.62 \%$ increase under 2SLS. Then, a $1 \%$ increase in the foreign-born worker share among all highly-educated workers will lead to a statistically significant $0.24 \%$ increase in a native worker's communication unit supply and a significant $0.17 \%$ decrease in the manual unit supply in the WLS regressions approximately if we use both basic definitions for communication and manual tasks. However, the decrease in the manual unit supply is insignificant and smaller if we use extended definition for manual. That might be due to the inclusion of spatial and form perception which are not quite substitutable as professional aptitudes. Moreover, there might be some factor in the error term, such as a special immigration policy in some year for the emergent need of some types of laborers, impacting both the natives manual task unit supply and the foreign-born worker share in the labor market and hard to be generated as a variable, which could also affect the coefficient. When it comes to the 2SLS regressions, the increase in the communication task unit supply would be around $0.22 \%$ resulting from a $1 \%$ increase in the foreign-born share, while manual task unit supply would decrease by $0.40 \%$. Most of the results are statistically significant at the $5 \%$ level. From the results in the 2SLS regressions, we could verify the significantly negative relationship between the natives' manual task unit supply and the foreign-born worker share in the Canadian labor market.

Table 5 demonstrates the regression results for the less-educated native group. In this group, the results give us a similar pattern to the highly-educated group in Canada. An increase in the foreignborn worker share will cause the relative supply of communication versus manual tasks to increase, which means native workers will transfer to more language intensive jobs. An increase in the foreignborn share will also lead to an increase in the communication task unit supply and a decrease in the manual task unit supply from less-educated workers.

From these two tables, we can see that both within the highly and less-educated worker groups, the effects of immigration on natives appear quite similar. From these two tables, we can see that immigrants will push native workers transfer to supply more communication task and less manual task to prevent potential economic loss. Although the immigration requirement for immigrants' educational attainment and language proficiency is getting higher and higher, native workers still have a relative advantage in communication intensive jobs. In the less-educated group, I only find the insignificantly negative effect that natives supply fewer manual tasks per unit time when the share of less-educated foreign-born workers increases. Large part of workers could engage only in the low-level technical jobs in this group which have similar manual task supply productivity, so this makes the transfer from the low communication-intensive jobs to the higher ones insignificantly affect a worker's unit supply of manual task. 


\subsection{Effects From Immigration on Total Task Supply}

Similarly to what I did for the native workers group, in this part, I will study the effects on the total population from the foreign-born worker share. I still run three types of regressions in this part. One uses the relative supply of communication versus manual tasks in Canada, which is equation (14), while the other two use the average amount of communication (c) and manual (m) tasks supplied per unit time by the total population. I aggregate the supply of manual and language skills to generate the tasks supplied by the total population.

Tables 6 and 7 illustrate these results for both the high and lower-educated groups, respectively. Columns 1 and 3 use the basic-basic definitions while Columns 2 and 4 use the basic-extended definitions. In Table 6, the regressions yield significant and positive estimates for $\gamma_{T O T}$. This implies that an increase in the share of foreign highly-educated workers causes a mass of the population to transfer to communication-intensive jobs. More specifically, from the estimates of $\gamma_{T O T}^{C}$ and $\gamma_{T O T}^{M}$ I find that a 1 percent rise in the foreign born share in the highly-educated group will increase the communication task productivity of the total population by $0.18-0.22$ percent in all four regressions and decrease manual task productivity by 0.14 in the WLS and 0.40 in the 2SLS regressions. This implies that, with an increase in the share of highly-educated foreign born workers, the total highly-educated population will shift toward more communication intensive tasks $(\mathrm{C} / \mathrm{M}$ ratio) by increasing communication task productivity while decreasing manual task productivity at the same time. The results in Table 6 are opposite to the results in Peri and Sparber's (2009) study of the US, which indicates a significantly positive relationship between the foreign born worker share and the total population's relative task supply ( $\mathrm{C} / \mathrm{M}$ ratio). The reason might be that the immigrants coming to Canada are overwhelmingly skilled workers and business people, which are quite different from those going to the US. These types of immigrants in Canada may increase the demand for some communication-intensive jobs a lot, such as finance advisors, investment consultants, real estate agents, and new immigrant service positions. This high demand for communication-intensive jobs may encourage Canadian workers to transfer to these jobs to get highly paid. Meanwhile, since many immigrants chosen by Canada have good language skill and the same cultural background as their compatriots, they may also engage in communicationintensive jobs. These facts could cause an increasing relative supply of the communication versus the manual tasks of the total population in the Canadian labor market.

Table 7 shows the regressions for the lower-educated group. In this table, we can tell that almost all of the estimated coefficients are statistically insignificant. This confirms our prediction for the lower-educated workers in Canada. Since the foreign born share of the lower-educated population is quite small, the immigrant (the majority of whom have high educational attainment) will not affect this group much. This finding supports the idea that, different from the US, we should care more about the highly-educated immigrants who form the majority of the foreign-born workers in the Canadian labor market. 


\subsection{Effects From Immigration onto Task Compensations}

\subsubsection{Regression Model}

In this section, I study the immigration effects on the two task compensations, $w_{C}$ and $w_{M}$, by estimating equation (18). The first step of the empirical analysis is to generate these two task compensations since we do not observe the unit wage paid to manual or communication tasks but only the wage paid to workers in each occupation. Here I will use a two-step procedure for each CMA and year. I first generate real hourly wages $\left(w_{j s t}\right)$ for each metropolitan area, year and occupation within those two educational groups. In the second step, I regress $w_{j s t}$ on occupation specific measures of manual $\left(m_{j}\right)$ and communication $\left(c_{j}\right)$ skills. I allow coefficients on skills to vary across location and time. Hence, by running the regression in equation $(18)^{7}$, I will get the task compensations. After the running the regression, I will get the coefficients $\widehat{w}_{M_{s t}}$ and $\widehat{w}_{C_{s t}}$, and I will interpret them as the weekly compensation of a unit of manual and communication task.

$$
w_{j s t}=\left(w_{M}\right)_{s t} m_{j}+\left(w_{C}\right)_{s t} c_{j}+\varepsilon_{j s t}
$$

With these regression results, I am able to generate the relative compensation of communications and manual tasks $\left(\widehat{w}_{C} / \widehat{w}_{M}\right)$ for each CMA and each census year. After this, I will be able to introduce this compensation ratio variable into Equation (15) to derive the effects of immigration on task compensations.

\subsubsection{Regression Results}

Tables 8 and 9 demonstrate the results for the immigration effects on two educational groups' task compensation ratios, respectively. According to Table 8 which shows the effect on compensations for the highly-educated group, the coefficients from the weighted least square regressions are both positive using the basic-basic and basic-extended task definitions. This implies that the relative compensation of communication versus manual tasks has a positive relationship with the foreign-born share. Furthermore, when I estimate the regressions by 2SLS, the coefficients for both groups with different task definitions are statistically significant, which indicates a positive immigration effect on relative task compensation in the highly-educated labor market. However, when it comes to the less-educated labor market showed by Table 9, I find that all the results are insignificant. This implies that, in Canada, less-educated foreign-born workers will not significantly impact the ratio of communication versus manual task compensation.

Combined with the results in Section 5.2, we can see that, in the highly-educated group, the immigration effect in Canada could lead an increase both in equilibrium relative task supply and equilibrium relative compensation, which is showed by Figure 6 . An increase in immigration to Canada

\footnotetext{
${ }^{7}$ This is a non-constant regression model
} 
will shift the demand curve of $\mathrm{C} / \mathrm{M}$ rightward by a large distance. This increase will exceed the decrease of $\mathrm{C} / \mathrm{M}$ resulting from the leftward shift of the supply curve. Hence, we may see that an increase in immigration to Canada will lead to an increase both in the equilibrium relative tasks usage and the equilibrium relative tasks compensation.

Here are some other explanations for this result. Laryea (1998b) shows that the foreign-born share in the Canadian labor market has a high-elasticity complementary effect on Canadian wages in some communication-intensive industries and a lower-elasticity substitutable relationship in other industries. For instance, more wealthy immigrants coming to Canada might increase the demand for some occupations such as finance advisor, investment consultant, new immigration service positions, and so on. The wages of these communication-intensive occupations will be increased quite dramatically, meanwhile, the substitution effect in the manual-intensive industries will lead to an increase in the relative compensation of the communication versus the manual tasks as well. This may generate a significantly positive relationship between the foreign born share and this relative compensation. Moreover, my instrument is slightly different from Peri and Sarber's (2009). My instrumental variable is based on some different countries of origin, which means the composition of immigrants I use is different, and hence I get different results from those in Peri and Sparber's paper. Then, for the less-educated labor market, since there is not much low skilled immigration relative to the entire low skilled population in the Canadian labor market, immigration may not have a dramatic impact on the less-educated labor market.

\subsection{Impacts Across Demographic Groups}

In this section, I study how the increase in foreign-born shares in high and less-educated groups would impact different demographic groups. First, I will still take studies on the two educational group respectively as what I did in previous sections. Then, I assume long-term immigrants are different from both new ones and native workers which means that they will perform specially under the effects

from the increase of new immigrants. Therefore, I want to take a look at the different immigration effects on natives and long-term immigrants.

\subsubsection{Impact on Long-Term Immigrants}

Column 1 in Tables 10 and 11 show the impact on long-term immigrants and natives from immigrants within two educational group. I have already described the impact on natives in Section 5.1. Thus, here I will focus on long-term immigrants. In both of these two groups, the impacts from new immigrants seem not to be quite significant. From the two 2SLS regression results, it appears that the rise in new immigrants will push the early- immigrated highly-educated workers to decrease their communication task supply while the early lower-educated ones increase their manual task supply. This means that new immigrants with higher educational attainment seem to be more substitutable with those early 
immigrants in the communication field. However, in the less educated group, long-term immigrants have a weaker tendency to respond to immigration by moving into communication tasks.

\subsubsection{Impact by Gender}

Column 2 in Tables 10 and 11 shows the immigration effects on different gender groups. Within both of the high and lower-educated worker groups, a rise in the immigrant share will make both male and female natives move to communication-intensive jobs. However, the magnitude of the response is larger for men in the highly educated group, but it is larger for women in the lower educated group.

\subsubsection{Impact on Age Groups}

In this paper, we also assume that the increase in immigrants will result in different magnitude of impacts on workers of different ages both in the two educational groups. As is shown by Columns 3 in Tables 10 and 11, most of the regressions give significant results. Within the highly educational group, the tendency to move away to communication-intensive jobs under the influx of immigrants is more significant among young workers. However, this tendency is more significant among elders when it comes to the less-educated workers group.

\subsubsection{Impact on Race Groups}

Now, I take the race discrepancy into consideration. From Column 4 in Tables 10 and 11, we can see that immigrants did not affect black workers' task supplies significantly either in the highly or lower educated workers group. Furthermore, an increase in immigration tends to shift native nonblacks to communication-intensive jobs in both of the two educational groups. It seems that black Canadians were less responsive to competition with immigrants.

\section{Conclusion}

The effects of immigration on the Canadian labor market depend on how the native workers respond to foreign-born workers' entry. In this paper, I apply Peri and Sparber's empirical procedures, guided by theoretical models, to study the immigration effects on two separate worker groups with different levels of education attainment. First of all, I assume that the production of goods and services occurs by combining different labor skills. Then, with the Canadian Career Handbook, I define communication and manual skills in two ways (basic and extended). By doing this, I generate communication and manual task variables for each occupation and combine these two variables with census data between

1971 and 2011 to undertake the empirical analysis. In Canada, there is a dramatic increase in the highly-educated immigrant population since the 1970s. Many of these new immigrants are considered 
to be more skilled than native workers and/or quite wealthy since quite a part of them are required quite strictly to pass the immigration points system (Warman, Webb, and Worswick, 2019).

From the results in this paper, we can draw some conclusions. First, foreign-born workers have led Canadian natives of all educational backgrounds to transfer to more communication intensive jobs. It may be that if immigrant workers from developing countries have high-level technical skill or language skill or both but are willing to supply labor at lower wages, they will be preferentially hired

by employers. Moreover, when it comes to the aggregate population, I find that larger parts of the population will engage in more communication-intensive jobs than before. According to the empirical results, I can claim that an increase in immigration will both increase the task compensation ratio and the aggregated task supply ratio of communication versus manual tasks in the highly educated Canadian labor market. However, we need to be aware that the aggregated task supplies of lower educated workers are not influenced by immigrants very significantly because the majority of immigrants to Canada highly educated workers.

Finally, when I divide the population into demographic groups, I find differences in task performances. Once again, because of the small population of low skilled immigrants coming to Canada, the task performance is different in these two educational groups in terms of demographic characteristics. These findings are quite different from those in Peri and Sparber's paper (2009) because the immigration situation in the Canadian labor market is quite different from that in the US. This deviation may lead a different equilibrium in Canada.

According to these results in this study, we may conclude that a different system of immigration from the US may generate a different task supply transition in the Canadian labor market. At the same time, language ability and cultural background still plays quite an important role in this immigration effect. Natives are still able to use their communication advantage to acquire benefits or avoid potential economic loss.

\section{References}

[1] Adserà A, Ferrer A M. The myth of immigrant women as secondary workers: Evidence from Canada[J]. American Economic Review, 2014, 104(5): 360-64.

[2] Adserà A, Ferrer A. Occupational skills and labour market progression of married immigrant women in Canada[J]. Labour economics, 2016, 39: 88-98.

[3] Aydemir A, Borjas G J. A comparative analysis of the labor market impact of international migration: Canada, Mexico, and the United States[R]. National Bureau of Economic Research, 2006.

[4] Baker M, Benjamin D. Labour market outcomes and the participation of immigrant women in Canadian transfer programs[J]. Diminishing returns: The Economics of Canada's recent immigration policy, 1995: 209-242. 
[5] Goldin C, Katz L F. The race between education and technology: The evolution of US educational wage differentials, 1890 to 2005[R]. National Bureau of Economic Research, 2007.

[6] Laryea S A. The impact of foreign-born labor on Canadian wages: A panel analysis[M]. Vancouver Centre of Excellence, 1998.

[7] Laryea S A. The Substitutablity and Complementarity of Canadian and Foreign-born Labour: Circa 1990[M]. Vancouver Centre of Excellence, 1998.

[8] Ottaviano GIP, Peri G. Immigration and national wages: Clarifying the theory and the empirics[R]. National Bureau of Economic Research, 2008.

[9] Peri G, Sparber C. Task specialization, immigration, and wages[J]. American Economic Journal: Applied Economics, 2009, 1(3): 135-69.

[10] Picot W G, Sweetman A. The deteriorating economic welfare of immigrants and possible causes[M]. Statistics Canada, Business and Labour Market Analysis Division, 2004.

[11] Schaafsma J, Sweetman A. Immigrant earnings: age at immigration matters[J]. Canadian journal of Economics, 2001: 1066-1099.

[12] Warman C, Webb M D, Worswick C. Immigrant category of admission and the earnings of adults and children: how far does the apple fall?[J]. Journal of Population Economics, 2019, 32(1): 53-112. 


\section{A tables}

Table 1: Occupations and Task Intensity

\begin{tabular}{|c|c|c|c|}
\hline Occupations & $\begin{array}{c}\text { Communication } \\
\text { intensity } \\
\text { index } \\
\end{array}$ & $\begin{array}{c}\text { Manual } \\
\text { intensity } \\
\text { index } \\
\end{array}$ & $\begin{array}{c}\mathrm{C} / \mathrm{M} \\
\text { percentile }\end{array}$ \\
\hline \multicolumn{4}{|c|}{ Four occupations with highest communication/manual values } \\
\hline Management Consultants & 0.75 & 0.33 & 0.992 \\
\hline Financial and Investment Analysts & 0.75 & 0.33 & 0.992 \\
\hline Financial Auditors & 0.75 & 0.33 & 0.992 \\
\hline Loan Officers & 0.75 & 0.33 & 0.992 \\
\hline \multicolumn{4}{|c|}{ Four occupations with average communication/manual values } \\
\hline Supervisors, Mining and Quarrying & 0.375 & 0.375 & 0.487 \\
\hline Operating Room Technicians & 0.375 & 0.375 & 0.487 \\
\hline Commissioned Officers, Armed Forces & 0.375 & 0.375 & 0.487 \\
\hline Petroleum, Gas and Chemical Process Operat & 0.375 & 0.375 & 0.487 \\
\hline \multicolumn{4}{|c|}{ Four occupations with lowest communication/manual values } \\
\hline Sewing Machine Operators & 0.15 & 0.46 & 0.008 \\
\hline Butchers and Meat Cutters, Retail and Whole & 0.15 & 0.50 & 0.006 \\
\hline Labourers in Food, Beverage and Tobacco Pr & 0.05 & 0.25 & 0.004 \\
\hline Labourers in Rubber and Plastic Products Ma & 0.05 & 0.25 & 0.002 \\
\hline
\end{tabular}

Note: This table shows groups of occupations with the highest, averavage, and the lowest $\mathrm{C} / \mathrm{M}$ ratios as well as the percentiles of them among all the occupations in the Canadian Census. 
Table 2: Occupations with the highest highly-educated workers share

\begin{tabular}{lcccc}
\hline \hline & $\begin{array}{c}\text { Communication } \\
\text { intensity } \\
\text { index }\end{array}$ & $\begin{array}{c}\text { Manual } \\
\text { intensity } \\
\text { index }\end{array}$ & $\begin{array}{c}\text { Manual-ext } \\
\text { intensity } \\
\text { index }\end{array}$ & $\begin{array}{c}\text { Highly-educated } \\
\text { workers' share (\%) }\end{array}$ \\
\hline Year 1991 & & & \\
\hline Specialist Phisicians & 0.73 & 0.67 & 0.70 & 100 \\
General Practitioners and Family Phisicians & 0.73 & 0.67 & 0.70 & 100 \\
Veterinarians & 0.73 & 0.75 & 0.79 & 100 \\
Medical Sonographers & 0.38 & 0.50 & 0.50 & 100 \\
Dietitians and Nutritionists & 0.50 & 0.25 & 0.35 & 100 \\
\hline & Year 2001 & & & \\
\hline General Practitioners and Family Phisicians & 0.73 & 0.67 & 0.70 & 99.7 \\
Chiropractors & 0.50 & 0.75 & 0.75 & 99.6 \\
Psychologists & 0.73 & 0.25 & 0.30 & 99.5 \\
Audiologists and Speech-Language Pathologi & 0.63 & 0.25 & 0.35 & 99.4 \\
Specialist Physicians & 0.73 & 0.67 & 0.70 & 99.4 \\
\hline & Year 2011 & & 99.9 \\
\hline General Practitioners and Family Phisicians & 0.73 & 0.67 & 0.70 & 99.8 \\
Geological Engineers & 0.73 & 0.25 & 0.40 & 99.7 \\
Specialist Physicians & 0.73 & 0.67 & 0.70 & 99.6 \\
Optometrists & 0.63 & 0.50 & 0.60 & 99.6 \\
Veterinarians & 0.73 & 0.75 & 0.79 & \\
Note: This table shows groups of occupations with the highest shares of workers with educational attainment above high school as well &
\end{tabular}


Table 3: Occupations with the lowest highly-educated workers share

\begin{tabular}{|c|c|c|c|c|}
\hline Occupations & $\begin{array}{c}\text { Communicatior } \\
\text { intensity } \\
\text { index } \\
\end{array}$ & $\begin{array}{c}\text { Manual } \\
\text { intensity } \\
\text { index } \\
\end{array}$ & $\begin{array}{c}\text { Manual-ext } \\
\text { intensity } \\
\text { index } \\
\end{array}$ & $\begin{array}{c}\text { Highly-educated } \\
\text { workers' share (\%) }\end{array}$ \\
\hline \multicolumn{5}{|c|}{ Year 1991} \\
\hline Ironing, Pressing and Finishing Occupations & 0.15 & 0.42 & 0.35 & 16.3 \\
\hline Sewing Machine Operators & 0.15 & 0.50 & 0.50 & 17.4 \\
\hline Chainsaw and Skidder Operators & 0.15 & 0.42 & 0.40 & 20.2 \\
\hline Labourers in Fish Processing & 0.15 & 0.42 & 0.35 & 21.5 \\
\hline Logging Machinery Operators & 0.15 & 0.42 & 0.40 & 21.6 \\
\hline \multicolumn{5}{|c|}{ Year 2001} \\
\hline Harvesting Labourers & 0.15 & 0.42 & 0.35 & 14.5 \\
\hline Sewing Machine Operators & 0.15 & 0.50 & 0.50 & 22.5 \\
\hline Labourers in Fish Processing & 0.15 & 0.42 & 0.35 & 23.6 \\
\hline Fish Plant Workers & 0.15 & 0.33 & 0.30 & 24.9 \\
\hline Ironing, Pressing and Finishing Occupations & 0.15 & 0.42 & 0.35 & 25.4 \\
\hline \multicolumn{5}{|c|}{ Year 2011} \\
\hline Harvesting Labourers & 0.15 & 0.42 & 0.35 & 14.6 \\
\hline Fish Plant Workers & 0.15 & 0.33 & 0.30 & 23.4 \\
\hline Aquaculture and Marine Harvest Labourers & 0.25 & 0.33 & 0.30 & 25.0 \\
\hline Labourers in Fish Processing & 0.15 & 0.42 & 0.35 & 25.1 \\
\hline Logging Machinery Operators & 0.15 & 0.42 & 0.40 & 29.1 \\
\hline
\end{tabular}


Table 4: Foreign-Born Workers and the Native Supply of Tasks

(Workers with a degree higher than high school)

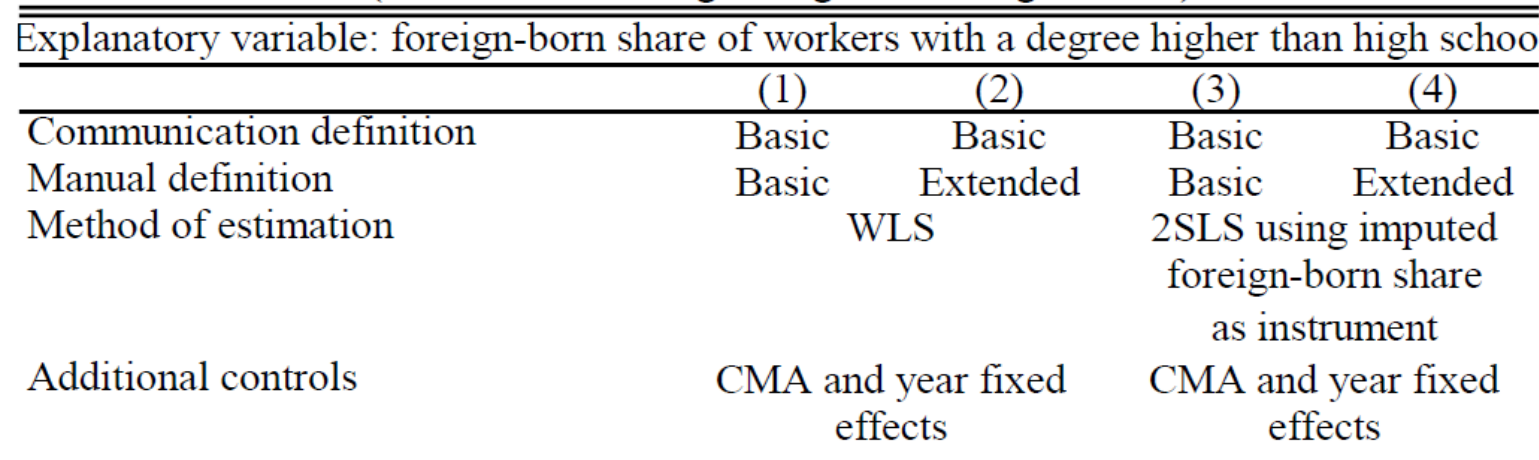

Dependent variables

$\begin{array}{llcccc}\ln \left(C_{D} / M_{\mathrm{D}}\right) & Y & 0.41 * * * & 0.34 * * * & 0.63 * * * & 0.61 * * * \\ \ln \left(c_{D}\right) & & 0.10 & 0.10 & 0.17 & 0.14 \\ & \gamma & 0.24 * * * & 0.24 * * * & 0.22 * * & 0.22 * * \\ \ln \left(m_{D}\right) & & 0.04 & 0.04 & 0.10 & 0.10 \\ & \gamma^{M} & -0.17 * * * & -0.10 & -0.41 * * * & -0.39 * * * \\ & & 0.07 & 0.08 & 0.10 & 0.10\end{array}$

First stage

Joint F-test of the instruments ( $p$-value) Observations

\begin{tabular}{lrrr} 
NA & NA & 7.59 & 7.59 \\
& & 0.01 & 0.01 \\
630 & 630 & 409 & 409 \\
\hline
\end{tabular}

Note: Each cell contains estimates from a separate regression. The dependent variable in each is indicated in the first column. The explanatory variable is the immigrant share of labor hours worked in the Census Metropolitan Areas(CMA) and year. All regressions include CMA and year fixed effects. The method of estimation in specifications (1)-(2) is weighted least squares. Regressions use employment as an analytic weight for each observation, and the standard errors are heteroskedasticity-robust and clustered by CMA. Specifications (3)-(4) use 2SLS using the imputed share of immigrants from chosen countries as the instrument. ***Significant at $1 \%$ level. **Significant at $5 \%$ level. 
Table 5: Foreign-Born Workers and the Native Supply of Tasks

(Workers with a high school degree or less)

\begin{tabular}{|c|c|c|c|c|}
\hline & $(1)$ & (2) & (3) & (4) \\
\hline Communication definitio & Basic & Basic & Basic & Basic \\
\hline Manual definition & Basic & Extended & Basic & Extended \\
\hline Method of estimation & \multicolumn{2}{|c|}{ WLS } & \multicolumn{2}{|c|}{$\begin{array}{l}\text { 2SLS using imputed } \\
\text { foreign-born share } \\
\text { as instrument }\end{array}$} \\
\hline Additional controls & CMA & fixed & $\mathrm{CM}$ & $\begin{array}{l}\text { ar fixed } \\
\text { s }\end{array}$ \\
\hline
\end{tabular}

Dependent variables

$\begin{array}{llcccc}\ln \left(C_{D} / M_{\mathrm{D}}\right) & Y & 0.18^{* * *} & 0.14 * * * & 0.23 * * * & 0.16^{* *} \\ \ln \left(c_{D}\right) & \gamma^{C} & 0.04 & 0.04 & 0.07 & 0.06 \\ & & 0.04 * * & 0.16^{* * *} & 0.14 * * * & 0.14 * * * \\ \ln \left(m_{D}\right) & \gamma^{M} & -0.02 & 0.04 & 0.05 & 0.05 \\ & & 0.02 & 0.02 & -0.09 * * & -0.02 \\ & & & 0.02 & 0.04 & 0.03\end{array}$

First stage

$\begin{array}{lcccc}\text { Joint F-test of the } & \text { NA } & \text { NA } & 21.06 & 21.06 \\ \text { instruments (p-value) } & & & 0.00 & 0.00 \\ \text { Observations } & 630 & 630 & 409 & 409\end{array}$

Note: Each cell contains estimates from a separate regression. The dependent variable in each is indicated in the first column. The explanatory variable is the immigrant share of labor hours worked in the Census Metropolitan Areas(CMA) and year. All regressions include CMA and year fixed effects. The method of estimation in specifications (1)-(2) is weighted least squares. Regressions use employment as an analytic weight for each observation, and the standard errors are heteroskedasticity-robust and clustered by CMA. Specifications (3)-(4) use 2SLS using the imputed share of immigrants from chosen countries as the instrument. ***Significant at $1 \%$ level. **Significant at 5\% level. 
Table 6: Foreign-Born Workers Aggregate Supply of Tasks and Communication-Manual Wage Elasticity

(Workers with a degree higher than high school)

\begin{tabular}{|c|c|c|c|c|}
\hline & (1) & (2) & (3) & (4) \\
\hline \multicolumn{5}{|c|}{ Panel A: Explanatory variable: foreign-born share of workers with a high school degree or less } \\
\hline Communication definition & Basic & Basic & Basic & Basic \\
\hline Manual definition & Basic & Extended & Basic & Extended \\
\hline Method of estimation & \multicolumn{2}{|c|}{ WLS } & \multicolumn{2}{|c|}{$\begin{array}{l}\text { 2SLS using imputed } \\
\text { foreign-born share } \\
\text { as instrument }\end{array}$} \\
\hline Additional controls & CMA and & ixed effects & CMA and & ixed effects \\
\hline
\end{tabular}

Dependent variables

$\begin{array}{llcccc}\ln (C / M) & \gamma_{\text {TOT }} & 0.35 * * * & 0.29 * * * & 0.63 * * * & 0.61 * * * \\ \ln (c) & & 0.08 & 0.08 & 0.16 & 0.14 \\ & \gamma_{\text {TOT }}^{c} & 0.18 * * * & 0.18 * * * & 0.22 * * * & 0.22 * * * \\ \ln (m) & & 0.04 & 0.04 & 0.08 & 0.08 \\ & \gamma_{\text {TOT }}^{M} & -0.17 * * * & -0.10 * * * & -0.41 * * * & -0.39 * * * \\ & & 0.05 & 0.06 & 0.11 & 0.11\end{array}$

First stage

$\begin{array}{lllll}\text { Joint F-test of the } & \text { NA } & \text { NA } & 7.59 & 7.59\end{array}$

$\begin{array}{llr}\text { (p-value) } & 0.01 & 0.01\end{array}$

$\begin{array}{lllll}\text { Observations } & 409 & 409 & 409 & 409\end{array}$

Note: Each cell contains estimates from a separate regression. The dependent variable in each is indicated in the first column. The explanatory variable is the immigrant share of labor hours worked in the Census Metropolitan Areas(CMA) and year. All regressions include CMA and year fixed effects. The method of estimation in specifications (1)-(2) is weighted least squares. Regressions use employment as an analytic weight for each observation, and the standard errors are heteroskedasticity-robust and clustered by CMA. Specifications (3)-(4) use 2SLS using the imputed share of immigrants from chosen countries as the instrument. ***Significant at $1 \%$ level. **Significant at $5 \%$ level. 
Table 7: Foreign-Born Workers Aggregate Supply of Tasks and Communication-Manual Wage Elasticity

(Workers with a high school degree or less)

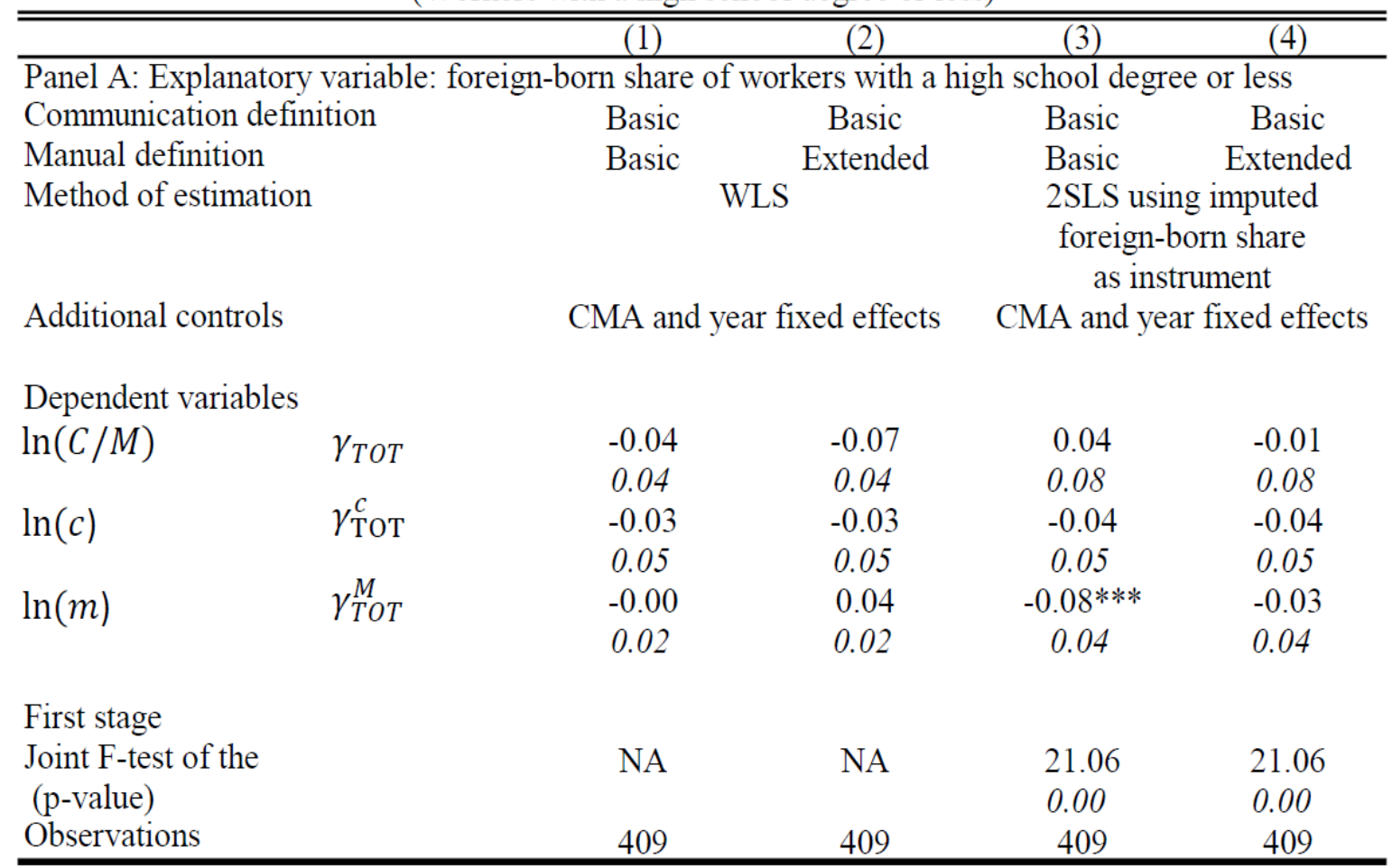

Note: Each cell contains estimates from a separate regression. The dependent variable in each is indicated in the first column. The explanatory variable is the immigrant share of labor hours worked in the Census Metropolitan Areas(CMA) and year. All regressions include CMA and year fixed effects. The method of estimation in specifications (1)-(2) is weighted least squares. Regressions use employment as an analytic weight for each observation, and the standard errors are heteroskedasticity-robust and clustered by CMA. Specifications (3)-(4) use 2SLS using the imputed share of immigrants from chosen countries as the instrument. ***Significant at $1 \%$ level. **Significant at $5 \%$ level. 
Table 8: Communication-Manual Compensation Ratio

(Workers with degree higher than high school)

\begin{tabular}{|c|c|c|c|c|}
\hline & (1) & (2) & (3) & (4) \\
\hline \multicolumn{5}{|c|}{ Panel: Explanatory variable: foreign-born share; dependent varibal $\notin n\left(w_{C} / w_{M}\right)$} \\
\hline \multirow{3}{*}{$\begin{array}{l}\text { Communication definition } \\
\text { Manual definition } \\
\text { Method of estimation }\end{array}$} & Basic & Basic & Basic & Basic \\
\hline & Basic & Extended & Basic & Extended \\
\hline & \multicolumn{2}{|c|}{ WLS } & \multicolumn{2}{|c|}{ 2SLS } \\
\hline \multirow[t]{2}{*}{$\gamma_{w}$} & 1.91 & 1.41 & $2.75 * *$ & $4.80 * * *$ \\
\hline & 1.13 & 1.08 & 1.36 & 1.31 \\
\hline \multicolumn{5}{|l|}{ First stage } \\
\hline Joint F-test of the & NA & NA & 136.77 & 137.59 \\
\hline (p-value) & & & 0.00 & 0.00 \\
\hline Observations & 402 & 402 & 402 & 402 \\
\hline \multicolumn{5}{|c|}{$\begin{array}{l}\text { Note: The dependent variable is the relative compensation to communication versus manual tasks. The } \\
\text { explanatory variable is the immigrant share of labor hours worked in the Census Metropolitan } \\
\text { Areas(CMA) and year. All regressions include CMA and year fixed effects. The method of estimation in } \\
\text { specifications (1)-(2) is weighted least squares. Regressions use employment as an analytic weight for } \\
\text { each observation, and the standard errors are heteroskedasticity-robust and clustered by CMA. } \\
\text { Specifications (3)-(4) use } 2 \text { SLS using the imputed share of immigrants from chosen countries as the } \\
\text { instrument. ***Significant at } 1 \% \text { level. **Significant at } 5 \% \text { level. }\end{array}$} \\
\hline
\end{tabular}


Table 10: Impact of Foreign-Born Workers on the Supply of Tasks Among Different Demographic Groups

(Controlling for individual characteristics in the construction of aggregate skills)

\begin{tabular}{|c|c|c|c|c|c|}
\hline \multicolumn{6}{|c|}{$\begin{array}{l}\text { Explanatory variable: foreign-born share among workers with a degree higher than high school } \\
\text { Dependent variables: relative communication/manual skills for the group, basic definition }\end{array}$} \\
\hline & & \multicolumn{4}{|c|}{ Only CA native worker are included in specifications (2) to (4) } \\
\hline & & $(1)$ & (2) & (3) & (4) \\
\hline Group 1 & & $\begin{array}{l}\text { Long-term } \\
\text { immigrants }\end{array}$ & Women & Young (18-40) & Black \\
\hline Group 2 & & Natives & Men & Old (41-66) & Non Black \\
\hline \multicolumn{6}{|l|}{ Dependent variables } \\
\hline Group 1, $\ln \left(C_{1} / M_{1}\right)$ & $\gamma$ & -4.69 & $0.51 * *$ & $0.82 * * *$ & 1.65 \\
\hline & & 2.69 & 0.22 & 0.20 & 1.85 \\
\hline Group $1, \ln \left(c_{1}\right)$ & $\gamma^{C}$ & $-2.05 * *$ & 0.17 & $0.36 * * *$ & 0.26 \\
\hline & & 1.00 & 0.14 & 0.10 & 0.80 \\
\hline Group 1, $\ln \left(m_{1}\right)$ & $\gamma^{M}$ & 2.64 & $-0.34 * * *$ & $-0.46 * * *$ & -1.39 \\
\hline & & 1.80 & 0.10 & 0.12 & 1.18 \\
\hline Group 2, $\ln \left(C_{2} / M_{2}\right)$ & $\gamma$ & $0.63 * * *$ & $0.77 * * *$ & $0.55 * * *$ & $0.65 * * *$ \\
\hline & & 0.17 & 0.19 & 0.15 & 0.17 \\
\hline Group $2, \ln \left(c_{2}\right)$ & $\gamma^{\mathrm{C}}$ & $0.22 * *$ & $0.34 * * *$ & 0.16 & $0.23 * *$ \\
\hline Group $2, \ln \left(m_{2}\right)$ & $\gamma^{M}$ & $\begin{array}{l}-0.41 * * * \\
0.10\end{array}$ & $\begin{array}{l}-0.43 * * * \\
0.11\end{array}$ & $\begin{array}{l}-0.39 * * * \\
0.09\end{array}$ & $\begin{array}{l}-0.41 * * * \\
0.10\end{array}$ \\
\hline Observations & & 409 & 409 & 409 & 409 \\
\hline \multicolumn{6}{|c|}{ 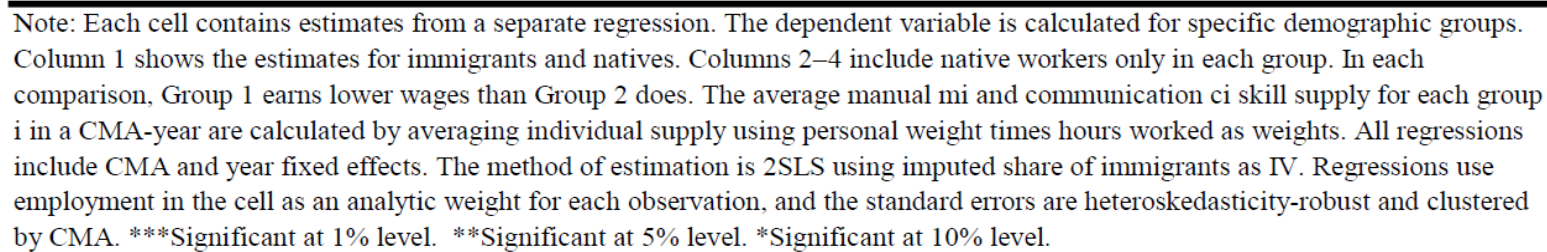 } \\
\hline
\end{tabular}


Table 11: Impact of Foreign-Born Workers on the Supply of Tasks Among Different Demographic Groups

(Controlling for individual characteristics in the construction of aggregate skills)

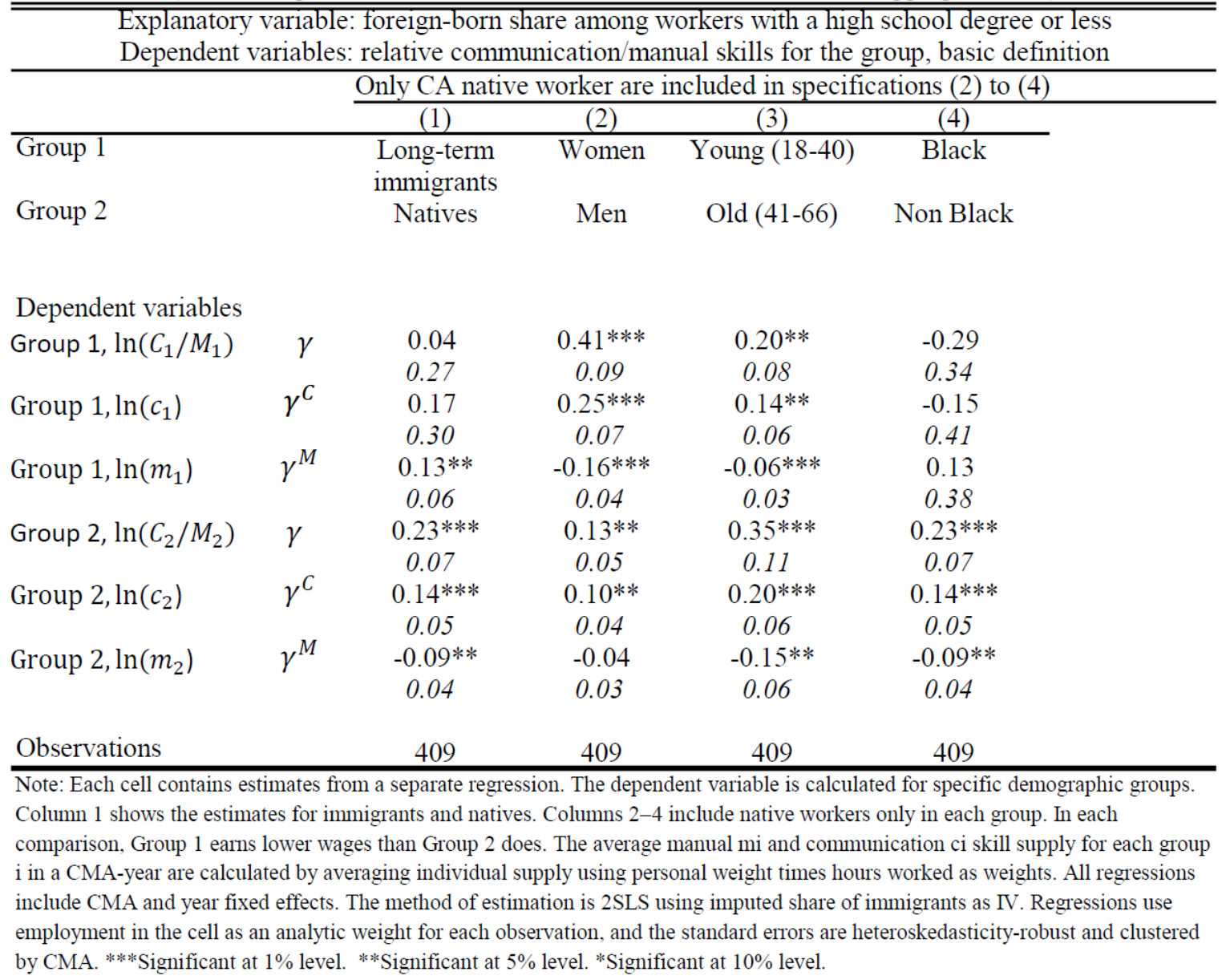




\section{B figures}

Figure 2: Equilibrium of the relative task supply and relative task compensation-Stage 1

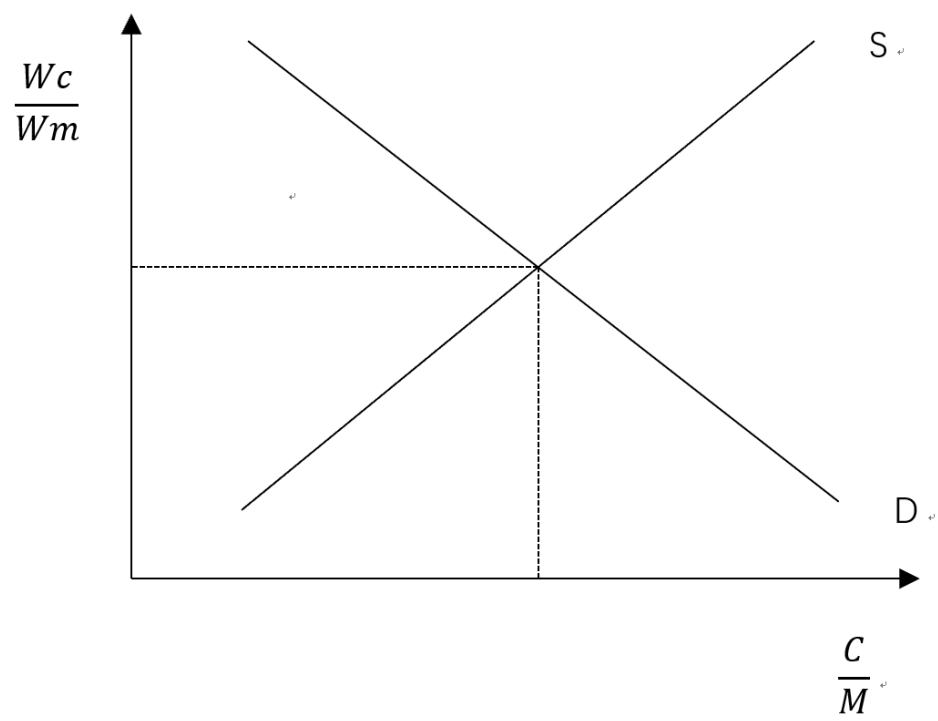


Figure 3: Equilibrium of the relative task supply and relative task compensation-Stage 2

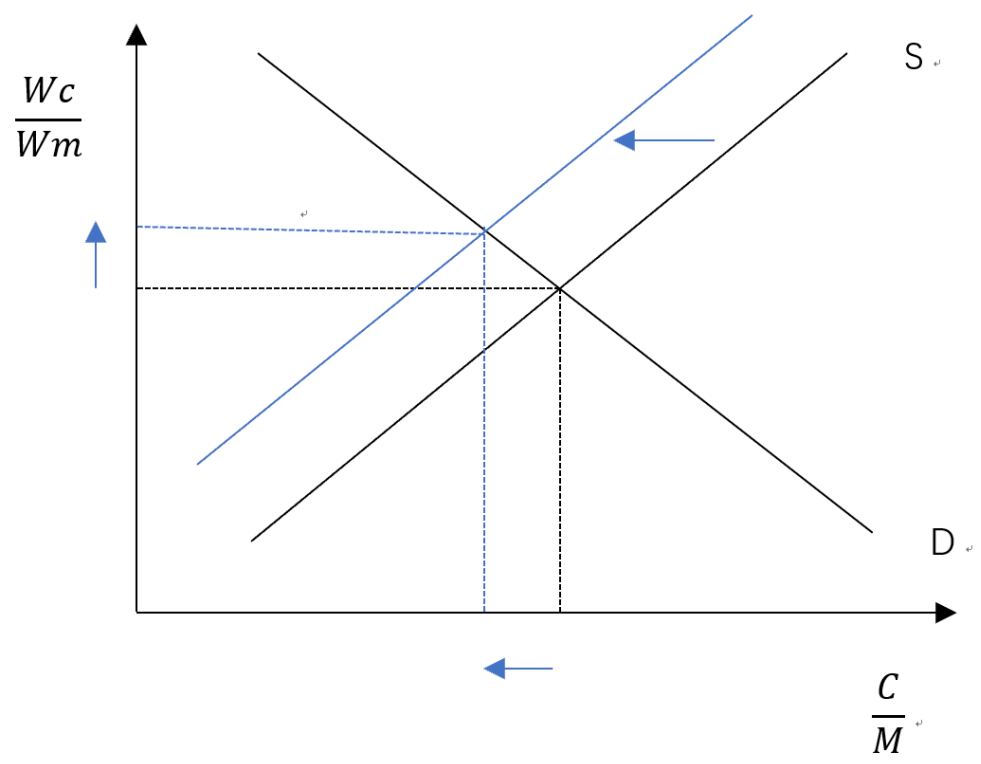

Figure 4: Equilibrium of the relative task supply and relative task compensation-Stage 3

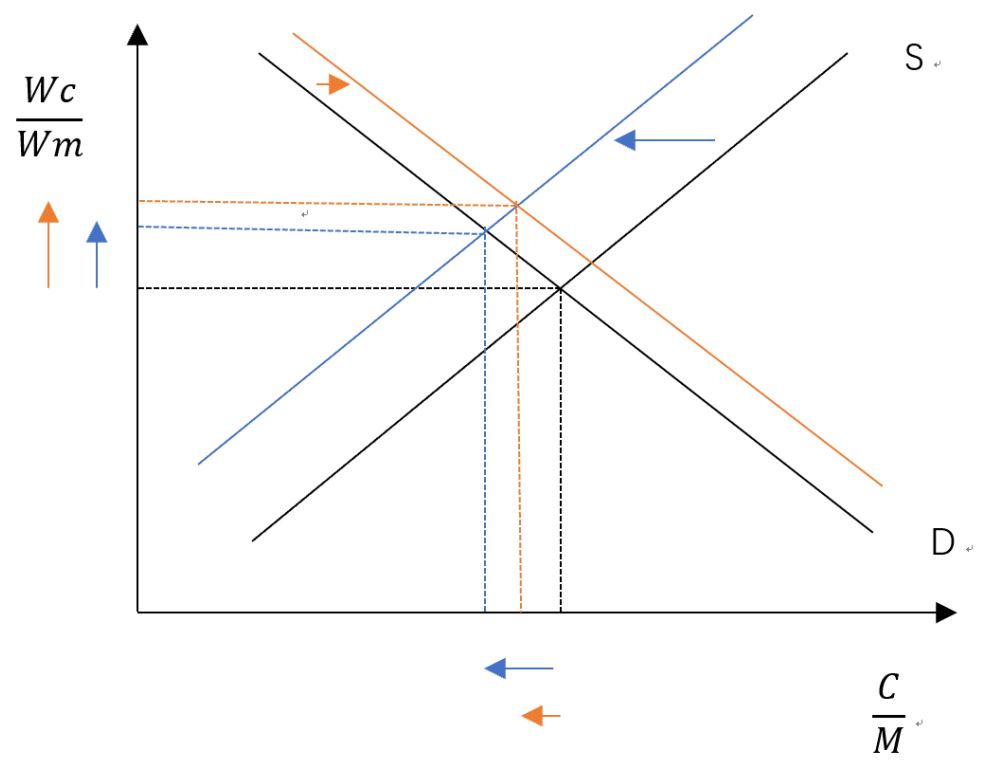


Figure 5: Equilibrium of the relative task supply and relative task compensation-Stage 4

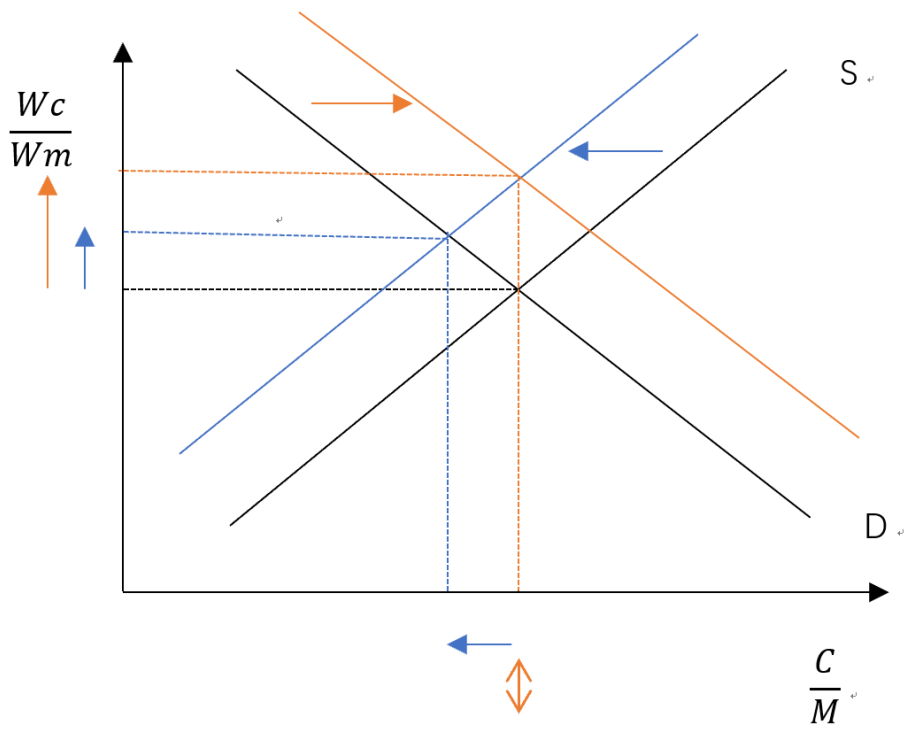

Figure 6: Equilibrium of the relative task supply and relative task compensation-Stage 5

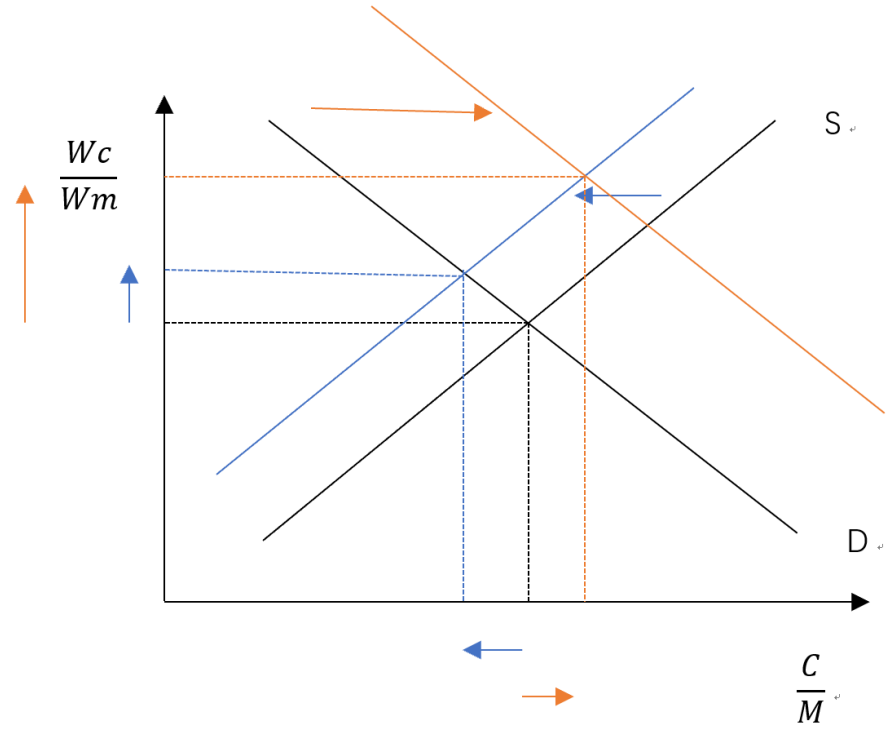


Figure 7: Communication intensive occupation population share in Canada

Ratio of population in high communication intensive occupations in Canada

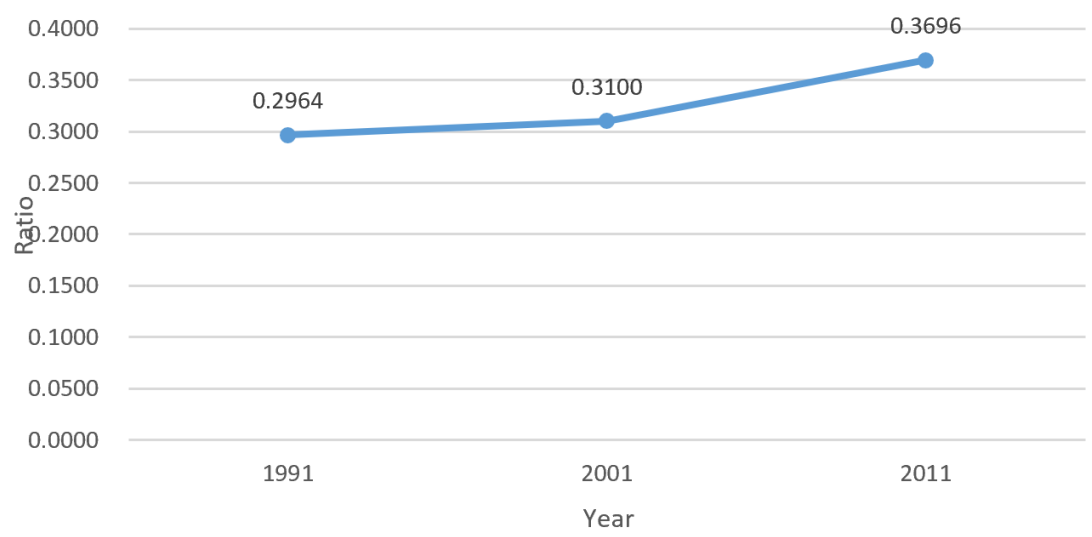

Figure 8: Communication intensive occupation population share in Canadian cities

Ratio of population in high communication intensive occupations in cmas

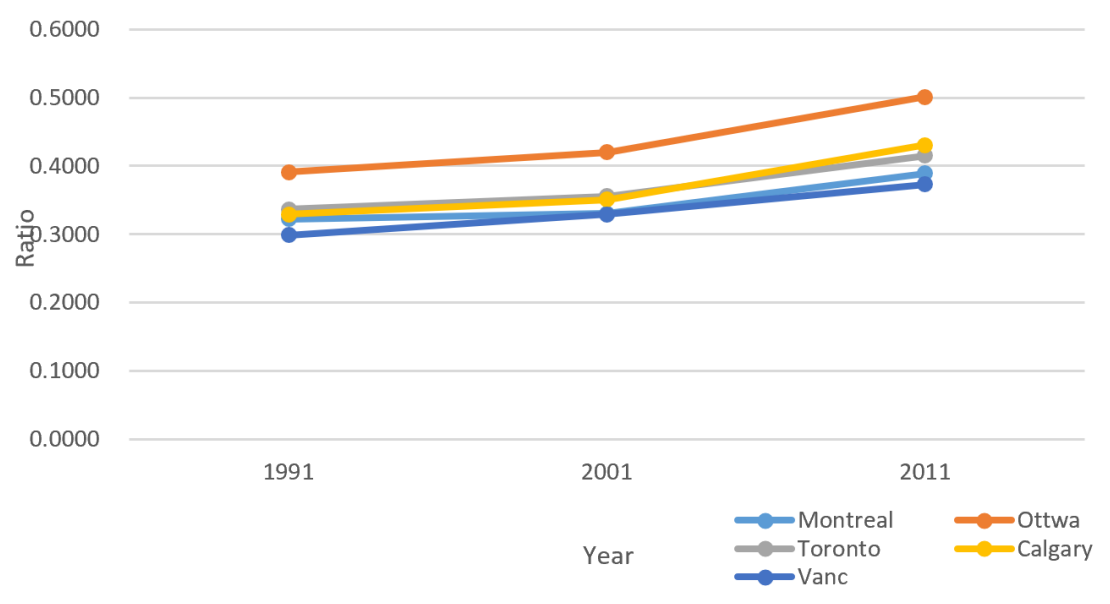

